doi http://dx.doi.org/10.18542/mri.v14i23.9183

\title{
CULTURA MATERIAL E IDENTIDADE: AS MÁSCARAS INDÍGENAS DOS POVOS TICUNA E PANKARARU
}

\section{MATERIAL CULTURE AND IDENTITY: THE INDIGENOUS MASKS OF THE TICUNA AND PANKARARU PEOPLE}

Rita de Cássia DOMINGUES-LOPES ${ }^{1}$

Universidade Federal do Tocantins - UFT

Resumo: O trabalho tem como objetivo apresentar e discutir a temática da cultura material como sendo um dos elementos importantes dos grupos humanos, assim, a produção e utilização desses elementos da cultura material marcam a identidade desses grupos. Nesta perspectiva, serão apresentados dois exemplos de cultura material através das máscaras: a máscara Taí ou Tae do povo indígena Ticuna (Amazonas) e a máscara Praiá do povo indígena Pankararu (Pernambuco). A pesquisa empreendida foi bibliográfica consultando referências reconhecidas sobre $\mathrm{O}$ assunto. Os resultados foram que os objetos, entre eles as máscaras, podem ser concebidos como elementos portadores de valores culturais, pois requer conhecimento e domínio de determinadas técnicas, do universo cosmológico, de relações próprias com o meio ambiente, a economia, a mitologia, os rituais, revelando o estilo de vida do grupo/povo e sua identidade.

Palavras-chave: Cultura material. Máscara. Povos indígenas.

\begin{abstract}
The work aims to present and discuss the thematic of the material culture as one of the important elements of human groups, thus, the production and use of these elements spot the identity of these groups. In this perspective, examples of the material culture will be presented through two masks: The Taí (also named as Tae mask) from the Ticuna indigenous people (located on Amazonas) and the Praiá mask from the Pankararu indigenous people (located on Pernambuco). The research method was bibliographic consulting recognized references on the subject. The results were that objects, including the masks, can be conceived as elements that carry cultural values, because it requires knowledge and mastery of certain techniques, of the cosmological universe, of unique relations with the environment, economy, mythology, rituals, revealing the lifestyle of the group/people and its identity.
\end{abstract}

Keywords: Material Culture. Masks. Indigenous People.

\footnotetext{
${ }^{1}$ Doutora em Antropologia (PPGA-UFPE). Professora na Universidade Federal do Tocantins, Campus Tocantinópolis. Coordena o Grupo de Pesquisa Cultura, Educação e Política (GP CEP/UFT). É membro do Núcleo de Estudos e Pesquisa Interdisciplinares da África e dos Afro-Brasileiros (NEAF/UFT). É sócia efetiva da Associação Brasileira de Antropologia (ABA) desde 2000. E-mail: ritadomingueslopes@ gmail.com
} 


\section{INTRODUÇÃO}

O trabalho tem como objetivo apresentar e discutir a temática da cultura material como sendo um dos elementos importantes dos grupos humanos e que sua produção e utilização marcam a identidade desses grupos. Nesta perspectiva, apresentarei dois exemplos de cultura material através das máscaras rituais: a máscara Taí ou Tae do povo indígena Ticuna (estado do Amazonas) e a máscara Praiá do povo indígena Pankararu (estado de Pernambuco). Para tal reflexão e análise a metodologia utilizada no artigo foi de uma pesquisa bibliográfica utilizando autores considerados clássicos no estudo da cultura material e no campo da Antropologia como Franz Boas, Berta Ribeiro, Ulpiano de Menezes, Raul Lody entre outros, assim como em autores/as que pesquisam os dois povos indígenas citados como João Pacheco de Oliveira Filho, Jussara Grüber e Priscila Faulhaber, Cláudia Mura, Marcos Albuquerque entre outros.

O texto consistirá além da introdução, de um subitem tratando brevemente da definição e importância da cultura material nas sociedades humanas e um dos campos de estudo da Antropologia; outro subitem apresentando as máscaras, seus contextos e identidades revelando que são objetos portadores de valores culturais, porque demonstra a necessidade de conhecimento e domínio de determinadas técnicas, do universo cosmológico, de relações próprias com meio ambiente, economia, mitologia e rituais, por fim, as considerações finais.

\section{CULTURA MATERIAL - DEFINIÇÃO E IMPORTÂNCIA}

A cultura material é um dos aspectos estudados nas sociedades humanas pelos antropólogos, arqueólogos, museólogos e outros profissionais, sendo que cada área do conhecimento tem seus métodos, técnicas e teorias próprios. A antropóloga Berta Ribeiro escreveu que "[...] um argumento irretorquível dos que defendem os estudos de cultura material é o de que eles refletem em seu conjunto, a ecologia, a economia e, em função disso, o estilo de vida dos povos [...]" (RIBEIRO, 1985, p.13).

Segundo o historiador Ulpiano de Meneses a cultura material é um “[...] segmento do meio físico que é socialmente apropriado pelo homem. Por apropriação social convém pressupor que o homem intervém, modela, dá forma a elementos do meio físico, segundo propósitos e normas culturais." (1983, p.112), portanto, não é aleatória e nem individual como diz Meneses, a produção da cultura material nesse nível é coletiva, segue elementos que marcam a identidade do grupo/povo que o produz, utilizando matérias-primas disponíveis no seu espaço de moradia e convivência. 
O estudo da cultura material, segundo Ribeiro, engloba os sistemas tecno-econômico e míticoritual. Os artefatos podem ser explicados pelo sistema tecno-econômico quando relacionados "[a]os recursos naturais disponíveis para a subsistência e o seu manejo pelas populações locais.” (1990, p.17), e pelo sistema mítico-ritual por estarem relacionados com “"...] a mitologia, a ritualística e a etno-estética que contribuem para a reprodução social e a identidade [...]” (1990, p.17). Trabalhando com estes dois sistemas complementares no que concerne à materialidade da cultura preservada em museus e universidades, compreendemos as condições em que foi/é produzida por atores sociais envolvendo questões ideológicas e ecológicas, conteúdos concretos e simbólicos de cada sociedade (RIBEIRO, 1990). Tais aspectos foram destacados porque o estudo dos objetos fabricados por um grupo humano não pode ser desvinculado do contexto em que são produzidos e utilizados.

Há uma diversidade cultural entre os povos indígenas em muitos aspectos e para fins desta pesquisa destaca-se a cultura material que pode ser vista enquanto testemunhos e documentos dos grupos sociais. Testemunho no que concerne "[...] ao conhecimento técnico, a visão do mundo, [na relação entre] homem e sociedade, dialogando, na tentativa de dizer quem ele é pelo que faz, significando para si e para o seu grupo valores [...] decodificados por quem vivencia." (LODY, 1986, p.152), desta maneira, revelam um conjunto de expressões materiais e imateriais desenvolvidas pelo grupo produtor.

Os bens materiais, produzidos por diversos povos indígenas e não indígenas, refletem tradições e saberes próprios, particulares a cada um, marcando suas identidades. Deste modo, a produção dos objetos caracteriza os povos, como por exemplo, os Xikrín (Pará) que se destacam pela plumária e pela cestaria; os Ticuna (Amazonas) por suas máscaras e vestimentas fabricadas a partir da entrecasca de árvore, onde são feitos desenhos e pinturas; os Karajá (Tocantins) pela produção das bonecas de barro Ritxòkò, entre outros exemplos. Somadas a estas particularidades em que se pode identificar o grupo produtor, observa-se também as categorias artesanais, a utilização de certas matérias-primas próprias de cada região e o contexto em que foram produzidos. Partindo dessa perspectiva, o artefato é vetor de identidade(s) e “[...] veículo de comunicação que traz consigo noções de status, idéias [sic], valores, sentimentos e significados." (FLEMING apud RIBEIRO, 1994, p.197). Gonçalves corrobora com esta perspectiva, quando afirma que os objetos passaram a ser vistos "como meios de demarcação de identidades e posições sociais." (1995, p.59).

A importância de se estudar a cultura material de uma sociedade se faz à medida que ela integra um conjunto de expressões desenvolvidas por essa mesma sociedade e implica tanto as relações com o meio ambiente quanto às questões socioeconômicas e culturais, as quais são reveladoras de vários aspectos, como: valores, costumes e tradições manifestadas pelo grupo, 
expressando, deste modo, um estilo de vida. Os bens materiais produzidos pela comunidade tendo como pano de fundo a perspectiva de que são criações culturais concretas de homens e mulheres, esses bens refletem características do passado e do presente.

Para discutir significados e signos da cultura material o antropólogo Franz Boas considera que um mesmo objeto pode implicar em um ou mais significados e "[...] a arte e o estilo característico de um povo, são compreensíveis somente se estudarmos a totalidade de suas produções [...]" (apud LOWIE, 1946, p.176). Segundo Boas, na tentativa de entender os significados de tais objetos, é preciso realizar trabalho de campo, conviver por um tempo com o grupo para observar o uso dos objetos; ouvir a explicação dada pelo próprio grupo sobre origem, feitura, decoração do objeto; é anotando com parcimônia se há alguma explicação mitológica sobre o artefato em foco (DOMINGUES-LOPES, 2002).

Quando Boas indica a necessidade de realizar trabalho de campo para descobrir e revelar os significados dos objetos, ele se refere à produção de etnografia, isto é, inscrever o discurso social no papel. Os antropólogos, assim, estariam exercitando a "descrição densa" como denominou o antropólogo Clifford Geertz (1978) considerada de "segunda mão" porque a primeira seria do próprio nativo e interlocutor da pesquisa.

A seguir trataremos de um elemento que faz parte da cultura material que são as máscaras, artefato importante em várias sociedades. Os casos escolhidos demonstram a variedade de matériasprimas, de fabricação e uso, mas ambas as máscaras são usadas em momentos rituais de iniciação seja feminina ou masculina.

\section{AS MÁSCARAS}

Segundo Berta Ribeiro em seu Dicionário do Artesanato Indígena (1988), as máscaras fazem parte da categoria artesanal Indumentária Ritual de Dança que tem por definição "vestimenta/disfarce composta de máscara - solta ou parte integrante da vestimenta - que figura seres sobrenaturais antropomorfos ou zoomorfos, e/ou simples capa de fibras vegetais que oculta o usuário." (1988, p.285). Corresponde a todo o conjunto que compõem a indumentária, ou seja, a cabeça, a vestimenta e/ou saiote, ou o traje que cobre todo o mascarado, da cabeça aos pés, e não apenas a "cara" ou a "cabeça".

Segundo o antropólogo Claude Lévi-Strauss (1989), as máscaras não podem interpretar a si mesmas porque fazem parte de um todo e de um contexto próprio, e nem por si mesmas, ou seja, como objetos separados de outros elementos, mas precisam do ritual e de outros elementos como a 
lança, o bastão, o tambor, para contextualizá-las, pois cada tipo de máscara está ligado à determinados objetos complementares. Não se deve considerar apenas o ponto de vista plástico das máscaras, mas também a sua representação e o momento que entra no ritual, cuja ênfase e cores determinadas pelos povos assumem uma individualidade própria.

O envolvimento social das máscaras reflete uma situação específica dos grupos humanos em um contexto social mais amplo de relações, uma vez que o uso das máscaras pode ser "[...] encontrado em grande número de povos." (BOAS, 2005, p.31). Boas considera que a origem do costume de utilizá-las não está clara em todos os casos, então, as máscaras teriam vários usos: desde a proteção do portador em relação aos espíritos maléficos à personificação de algum espírito ou à comemoração e representação teatral de seus ancestrais.

Desta forma, Lévi-Strauss (1989, p.18) considera que “[...] a cada tipo de máscara se veiculam os mitos que têm por objeto explicar sua origem lendária e sobrenatural, e fundar seu papel no ritual, na economia [...]" e em outros níveis da vida. Assim, percebendo a ligação entre o mito, os objetos e as Festas, as máscaras e os instrumentos musicais representariam peças significantes - simbólicas e sociais - na organização da própria sociedade.

\section{MÁSCARA TAÍ OU TAE - POVO INDÍGENA TICUNA² (ESTADO DO AMAZONAS)}

As máscaras e os instrumentos musicais produzidos pelos povos estão associados a determinados aspectos de vida, de visão de mundo e de organização social. Entre os Ticuna, estão associados a aspectos religiosos e míticos por seguir uma tradição, repassada e rememorada em cada Festa da Moça Nova aos mais novos membros do povo.

Nesta Festa existem tipos de pinturas faciais e corporais, músicas específicas segundo a nação/clã, assim como a existência de determinados papéis no ritual que somente são realizáveis por pessoas da mesma nação/clã ou de nação/clã oposta à da moça nova. Essa divisão acontece também com o uso dos instrumentos musicais e das máscaras (OLIVEIRA FILHO, 1988; CAMACHO, 1995, DOMINGUES-LOPES, 2000).

Entre os Ticuna, as máscaras podem representar tanto um desejo dos convidados como um produto da imaginação como demônios, quanto os animais retratados nos mitos (DOMINGUESLOPES, 2000). As máscaras e os panos de líber Ticuna são preparados com entrecasca de árvore,

\footnotetext{
${ }^{2} \mathrm{O}$ povo indígena Ticuna se autodenomina Magüta vive em várias Terras Indígenas no oeste do estado do Amazonas, próximo à fronteira da Colômbia e Peru. A população é de 53.544 habitantes de acordo com os dados da Siasi/Sesai de 2014 e é considerado um dos povos mais numerosos na Amazônia brasileira. A língua falada é Tikuna, pertencente ao tronco linguístico Tikuna. (ISA, 2020).
} 
conhecida na Amazônia como tururi que compreende várias espécies. Para retirar a entrecasca de uma árvore, ou seja, a parte mais tenra; raspa-se a epiderme da casca, apanha-se a entrecasca e coloca-se imersa em água, que a seguir, é batida de macetes até que os panos se desprendam do linho, os quais são lavados no rio e posto para secar ao sol esse processo foi descrito por Frota (1981).

Os Ticuna cortam os troncos de árvores no tamanho necessário para preparar as máscaras. Quando o pano está seco são pintados com pigmentos naturais e depois são costurados lateralmente com agulha de osso e fio de tucum para formar o corpo da vestimenta, acrescida posteriormente, se for o caso, de mangas que se estendem até a mão, e de franjas. Existem também máscaras que são retiradas inteiras do tronco, isto é, "[...] removidas da madeira como peça tubular inteiriça [...]" (VINCENT, 1987, p.153) não precisando, desta forma, serem costuradas lateralmente.

As máscaras são preparadas com matérias-primas retiradas da natureza, como: líber de caxinguba (Ficus Radula Willd), matá-matá (Chytroma Turbinata Berg Mierg), fio de tucum (Astrocaryum vulgare), madeira pau-de-balsa (Ochroma lagopus Swartz), cortiça de buriti (Mauritia flexuosa L.), tala de arumã (Ischnosiphon spp.) ou ainda com materiais adquiridos depois do contato com o branco como vidro (espelho), louça, alumínio (DOMINGUES-LOPES, 2000). As tintas para pintura das máscaras são de origem vegetal e mineral, a saber: o amarelo é retirado da argila terrosa e do rizoma do açafrão (Dieffenbachia humulis); o marrom é retirado das folhas do tariri; o preto é do breu (resina preta de anani Maronobea sp.) e do jenipapo (Genipa americana L.); o azul claro é do anil (Indigofera suffrutticosa Mill); o azul escuro é retirado do fruto da pacova (Renealmia sp.). (NIMUENDAJÚ, 1959; RIBEIRO, 1988; GRÜBER, 1992).

O formato das vestimentas, segundo Nimuendajú (1959) passou por um processo de modificação, possivelmente depois do contato com o branco, sendo que antes, elas eram feitas sem mangas, com franjas, em forma de vestido tubular estendendo-se até o joelho como verificou-se na vestimenta de máscara Taí ou Tae (Figura 1). Modernamente passaram para a forma de vestimenta inteiriça formando calça comprida, com mangas e franjas.

Figura 1. Vestimenta de máscara Taí ou Tae Coleção Curt Nimuendajú (1942) do Museu Paraense Emílio Goeldi

Vestimenta de máscara Taí ou Tae frontal

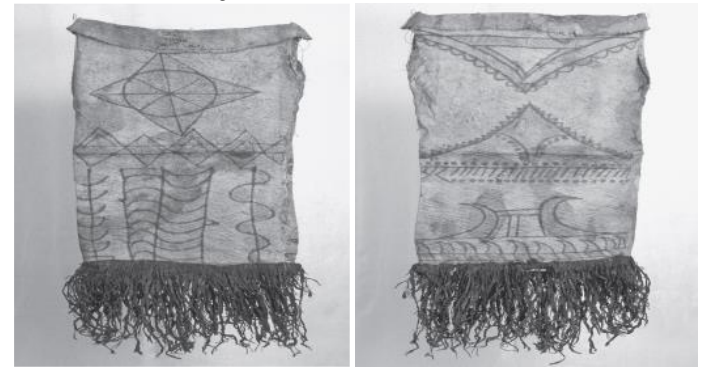

Fonte: FAULHABER, 2007, p.358.
Vestimenta de máscara Taí ou Tae dorsal 
A seguir, na Figura 2, é possível observar as máscaras sendo utilizadas no Ritual da Moça Nova entre os Ticuna no ano de 2014, como apresenta a antropóloga May Costa (2015).

Figura 2. Máscaras utilizadas em 2014

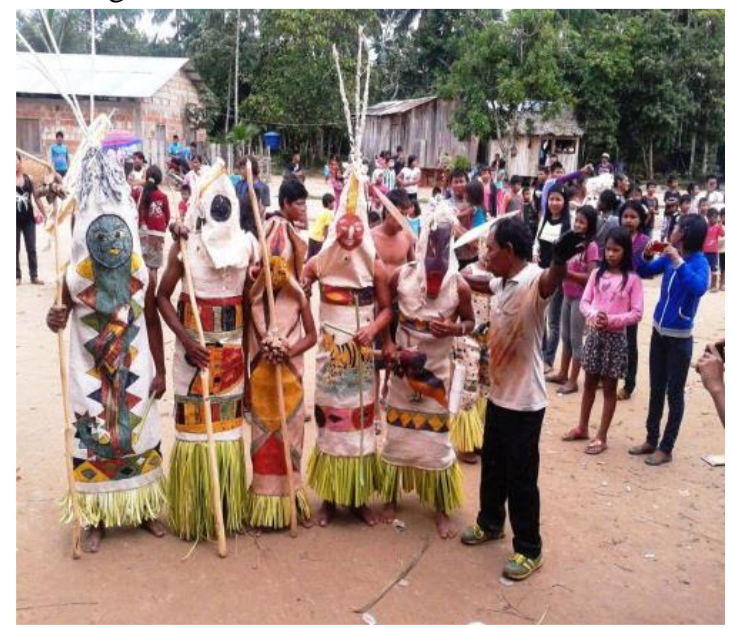

Fonte: COSTA, 2015, p. 75

A fabricação das máscaras, segundo Fajardo \& Torres (1988), é realizada por homens para serem usadas no ritual da Festa da Moça Nova. A antropóloga Jussara Grüber (1992) afirma que tanto a confecção e uso das máscaras pertencem ao domínio masculino e que também seriam os homens que fabricariam os instrumentos musicais e os bastões esculpidos. Em 2015 Costa corrobora com a afirmação de que a produção é masculina. Informação diferente foi obtida pelo antropólogo Hugo Camacho (1996) entre os Ticuna no território colombiano em que a fabricação das máscaras é tarefa das mulheres, assim como a produção dos colares, pulseiras, esculturas e as tarefas domésticas.

As máscaras são inseridas em um contexto maior de relações, envolvendo um processo que vai da busca de matérias-primas recolhidas na floresta ou conseguidas através de troca ou de compra nas comunidades não indígenas mais próximas, à elaboração, compreendendo os significados atribuídos e observados no conjunto de mitos relatados antes e durante a Festa, demonstrando, desta maneira, aspectos da identidade Ticuna, que informa sobre a organização social, cultural e econômica do grupo. (DOMINGUES-LOPES, 2000).

A máscara seria a representação plástica do mito e suas formas geralmente são representações zoomorfas como animais quadrúpedes, peixes, pássaros e entes sobrenaturais da floresta. O uso das máscaras e dos instrumentos musicais perpetuaria o ciclo de vida, pois seriam utilizados tanto nos nascimentos e nos casamentos quanto na Festa da Moça Nova (VINCENT, 1987). Este é considerado o principal rito entre os índios Ticuna, além dele, há outros como: a pintura de jenipapo no corpo das crianças pequenas, a nominação das crianças, o corte do cabelo das crianças, a perfuração das orelhas das crianças e o corte de cabelo das moças meses após a realização de sua festa. 
As máscaras e os instrumentos musicais e de sinalização representam símbolos importantes para a continuidade da Festa da Moça Nova. A presença dos instrumentos musicais serve tanto para marcar os passos durante a Festa, quanto convidar pessoas a participarem da mesma. Servem, ainda, para: atrair animais, ter prosperidade na caça, na pesca e na coleta de frutos, desejar/predizer longevidade às pessoas da aldeia, seguindo, a tradição na realização das festas, ou seja, a consolidação cada vez mais forte do grupo, tentando evitar maiores conflitos internos, visto que a luta contra os "brancos" é secular e eles precisam fortalecer-se. (DOMINGUES-LOPES, 2000).

A Festa representa um aspecto fundamental para a identidade Ticuna, a sua não realização segundo o mito de origem traz consequências maléficas como: doenças, escassez de alimento, má colheita, morte dos membros do grupo e através da natureza o seu herói fundador, Yoí, demonstraria sua força com períodos secos ou chuvosos. (CAMACHO, 1995).

Assim, as máscaras envolvem um conjunto de ações partindo desde a coleta e separação das matérias-primas, passando pela fabricação até chegar no uso durante a Festa. As máscaras fazem parte de um mito, juntamente com os instrumentos musicais e as pinturas corporais utilizadas na Festa. Assim, a realização do ritual é importante para a organização social do povo Ticuna.

\section{MÁSCARA PRAIÁ - POVO INDÍGENA PANKARARU ${ }^{3}$ (ESTADO DE PERNAMBUCO)}

Esta máscara faz parte do sistema ritual do Toré Pankararu que, segundo a antropóloga Claudia Mura, “[...] o toré é apenas uma parte dos rituais, mais especificamente aquela que fecha as sequências dos rituais e que abre a dança ao público que ficou assistindo.” (2012, p.292). O ritual está dividido em:

A) personagens: os Encantados, os Praiá, os pais de Praiá e os dançadores; B) situações rituais: o particular e o Toré público, que podem assumir o caráter de simples demonstrações teatrais, como expressão folclórica, ou serem dedicados ao culto dos Encantados, ligados ou não ao pagamento de promessas; e C) locais: as cachoeiras, serrotes, casas e terreiros. (ISA, 2020).

Segundo o antropólogo Marcos Albuquerque (2013/2014, p.184)

o praiá é usado em uma dança cerimonial coletiva realizada como ato final de uma série ritual centrada na instituição da 'promessa' (dádiva que se contrai com um ser espiritual). A dança cerimonial figura como congraçamento coletivo [entre o Encantado, o dançarino que usa roupa e máscara de ouricuri ou croá, devidamente

\footnotetext{
${ }^{3} \mathrm{O}$ grupo indígena Pankararu mora em terras indígenas com seu nome, com extensão de 8.377.2819 hectares, localizadas nos municípios de Petrolândia, Itaparica e Tacaratu, no sertão pernambucano, próximo ao rio São Francisco. A população é de 8.184 habitantes, dados da Siasi/Sesai de 2014. Disponível em: https://pib.socioambiental.org/pt/Povo:Pankararu. Acesso em 14 ago 2020.
} 
consagrada pelo zelador] e agradecimento de um feito milagroso, uma cura espiritual, atribuída à ação de uma entidade sagrada, genericamente chamada de encantado, cujo praiá é a representação material.

Durante os rituais as máscaras praiá personificam os encantados que são entidades sagradas que habitam na natureza (ALBUQUERQUE, 2017). Mura informa que são "apresentados como índios encantados em vida, isto é, índios que não passaram pela experiência da morte, mas por um processo de transformação, tornando-se imortais.” (2012, p.150. Itálico do original).

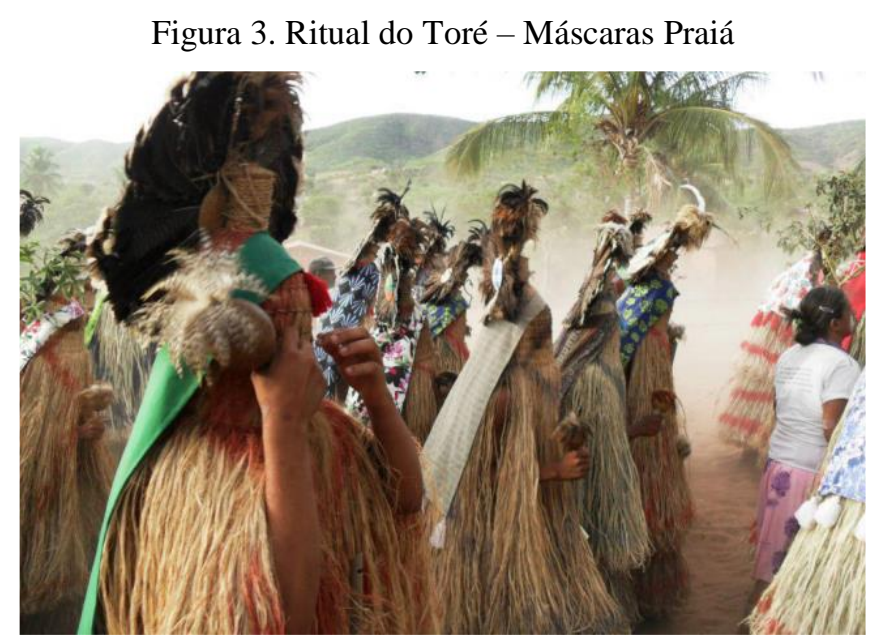

Fonte: ALBUQUERQUE, 2013/2014, p.350

Todo ritual do Praiá tem um zelador do encantado, como diz a descrição abaixo:

[...] que passará a ser também um 'pai de Praiá', deve confeccionar ou contratar a confecção, por um dos poucos artesãos especializados na aldeia, da roupa e da máscara de palha de ouricuri que servem para encobrir a personalidade do dançador e que é, quando vestida sob determinadas prescrições, a materialização do próprio Encantado.(ISA, 2020. Itálico do original).

Pelas descrições e fotos observadas nos trabalhos de Albuquerque (2013/2014 e 2017) e Mura (2012), além da máscara feita com a palha de ouricuri (Syagrus coronata (Mart.) Becc) ou croá (Neoglaziovia variegata) que cobrem todo o corpo do dançador/dançarino, tem sobre a cabeça acrescido um adorno plumário de cabeça considerado dentro das categorias artesanais elaborado por Berta Ribeiro (1988) como um diadema vertical rotiforme ${ }^{4}$ presos por um disco occiptal, e abaixo dele há um pedaço de tecido estampado que cai sobre as costas e nesse tecido pode ter algum bordado de símbolo religioso (Figura 4). ${ }^{4}$ Temos por definição "diadema rotiforme, usado na altura de vértex com as penas ornamentais irradiantes inseridas em
suporte semicircular." (RIBEIRO, 1988, p.120. Verbete Diadema vertical rotiforme). 


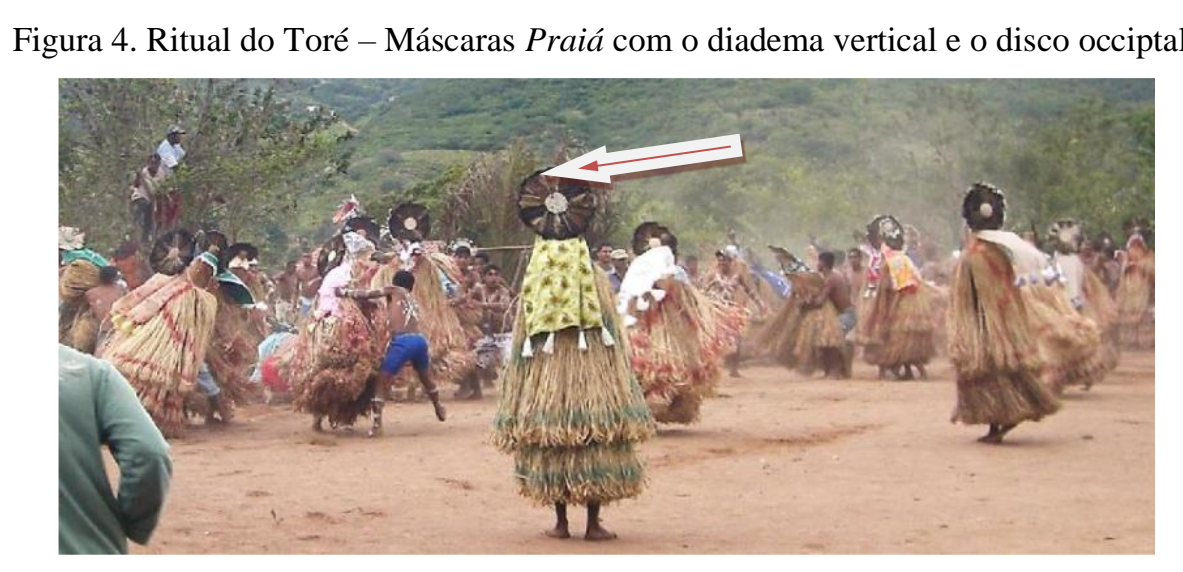

Fonte: MURA, 2012, p.303. *A seta foi colocada por mim para indicar o disco

No Dicionário do Artesanato Indígena, Ribeiro (1988, p.306) descreve uma "Máscara Capacete Plumário Pankararú" do Museu do Índio no Rio de Janeiro da seguinte forma:

Indumentária de dança dos índios Pankararú composta de três unidades: 1) capacete circular trançado revestido de uma fieira de penas de galo doméstico e penas de peru fixas no eixo superior do capacete; 2) gola de caraguatá ou agave que cobrem os ombros; 3) saiote da mesma fibra pintado de anilina. Acompanha a indumentária um bordão e chocalho para marcar o ritmo da dança.

$\mathrm{Na}$ descrição acima feita por Ribeiro as matérias-primas são outras: caraguatá (Bromelia pínguin L.) e agave (Agave americana $L$.) o que nos leva a pensar que com o passar do tempo a matéria-prima mudou na fabricação das máscaras, ou ainda dependendo do local onde as máscaras são fabricadas há um tipo diferente de matéria-prima utilizada, essas ponderações são hipóteses que precisam ser confirmadas ou refutadas com trabalho de campo, o que vai além deste artigo.

A descrição desse conjunto que forma a máscara Praiá cobre todo o dançador/dançarino deixando somente os pés de fora demonstrando a importância de todas as partes que compõe a máscara, portanto, assim como nos Ticuna as máscaras fazem parte de um ritual, entre os Pankararu é esperado que aconteça tanto dentro das aldeias como ritual quanto pode ocorrer fora das aldeias como uma brincadeira, que também marca a identidade.

Durante o ritual dois papéis se destacam: o de zelador e o de dançadores. Aos zeladores compete "um papel mais religioso, de orientação e guarda da tradição, através do cuidado com as sementes que lhes foram transmitidas, com as roupas dos Praiás e com o contato permanente com os Encantados, funções que normalmente se associam às qualidades de rezador e pai de família." (ISA, 2020).

Os dançadores "são normalmente homens jovens, casados ou não, capazes de 'segurar a brincadeira' do Toré, já que ela geralmente implica em muitas horas seguidas de dança dentro de 
pesadas roupas de palha de ouricuri, ou fibras de croá, e nos rituais do Menino do Rancho e da festa do Umbú, em disputas corporais que exigem grande vitalidade física.” (ISA, 2020). Os dançadores geralmente fazem parte do círculo familiar ou de afinidade do zelador da semente do Encantado.

A dança do Toré é regida por uma música fortemente compassada, o Toante, cantado por apenas um "cantador" ou "cantadora" e que encontra respostas periódicas nos gritos uníssonos e ritmados do grupo de bailarinos (ISA, 2020). Mura argumenta que o Toré pode ser tanto ritual quanto uma brincadeira, sendo que esta última pode ser apresentada em momentos diversos dentro ou fora da aldeia "os Pankararu podem decidir levar os praiás para dançar toré em circunstâncias e lugares em que é preciso mostrar a própria identidade étnica diante de um público que assim o solicite ou para afirmar a sua presença em um contexto como forma de reivindicação.” (2012, p.292. Itálico do original).

Os instrumentos que acompanham a música durante o toré são: o maracá, a gaita, o pífano e o rabo de tatu (BARROS; STEINER, 2013). Um dos símbolos sagrados da festa é o maracá feito do fruto do coité (Crescentia cujete), segundo Barros; Steiner “Os materiais utilizados na sua fabricação são canos de PVC, madeira (principalmente da umburana-de-cambão, Bursera leptophloeos) e cauda de tatu, respectivamente." (2013, p.243). A música é importante porque "chama a comunidade para os rituais [e chama] os encantados para formar o batalhão de praiás." (idem).

O conjunto formado pela máscara Praiá, representando os encantados, a presença dos instrumentos musicais, dos zeladores, dos cantadores e cantadoras faz do toré um ritual importante de identidade para o grupo. Como Mura (2015) e Albuquerque (2017) informam pode se tornar uma brincadeira, mas uma brincadeira para marcar sua identidade Pankararu.

Os objetos tornam-se parte da cultura material dos povos seja indígena ou não indígena. Prestar atenção em quem fabrica os objetos, sua forma de fazer utilizando uma matéria-prima específica e tendo um período para isso seja ritual ou não, prestando atenção também nas mudanças que o tempo provoca na sua fabricação e uso, marca vários processos identitários que podem ser pesquisados.

\section{CONSIDERAÇÕES FINAIS}

A presença da cultura material nos grupos humanos significa conhecimento e domínio de determinadas técnicas, do universo cosmológico, de relações próprias com o meio ambiente, a economia, a mitologia, os rituais e outros aspectos, revelando o estilo de vida do grupo e sua 
identidade. $\mathrm{O}$ estudo de cultura material é justificado pelo registro e por tudo aquilo que significa em termos de representação social e relações estabelecidas entre grupos.

As máscaras preparadas pelos povos indígenas expressam um estilo, uma estética própria que caracterizaria o povo e é também um veículo que comunica visualmente ideias e conceitos sobre o meio ambiente em que vivem, assim como sua visão de mundo e cultura (VINCENT, 1987).

Os objetos podem ser concebidos como elementos portadores de valores culturais. E o objeto etnográfico ocupa um lugar no conjunto de documentos tais como textos etnográficos, cadernos de campo, filmes documentários e fotografias, através dos quais é possível pensar usos e significados em uma cultura particular.

Tomando a cultura como um processo dinâmico de contínua invenção de tradições e significados, discute-se a possibilidade de um grupo indígena manter sua cultura quando este passa a adotar alguns costumes e objetos ocidentais/“dos brancos" como bens industrializados, percebe-se que a cultura dos grupos sociais é dinâmica, assimila certos elementos culturais de outros grupos atribuindo-lhes novos significados e rechaçando outros.

A incorporação de novos elementos à cultura significa a luta pela sobrevivência do povo, dentro de uma situação de contato interétnico onde tanto há uma tentativa de preservação dos símbolos já existentes como também daqueles que são incorporados. A identidade é construída a partir do contraste com os outros povos, onde cada um firma-se perante o outro, enquanto único e a exacerbação dos elementos étnicos próprios, são construídos não apenas por oposição ao outro, mas justamente para opor-se a ele, reconhecendo as devidas diferenças (CARDOSO DE OLIVEIRA, 1976; BRANDÃO, 1986).

Assim, como objetivo deste artigo foi apresentar e discutir a cultura material como um dos elementos que marcam as identidades dos grupos humanos, as máscaras foram os objetos escolhidos para essa reflexão, observa-se que as máscaras fazem parte de um sistema ritual que organiza a sociedade e é esperado por todos/todas que o ritual aconteça e dentre os preparativos para que o ritual seja realizado, destaco a fabricação das máscaras, as matérias-primas utilizadas, as pessoas que vão vesti-las no dia e o que representam para cada povo. Esses são alguns elementos em comum que podem ser destacados aqui, mas há outros que cada pesquisador/pesquisadora pode descobrir em novas pesquisas sobre o assunto.

Nos dois povos apresentados brevemente neste trabalho a situação de contato interétnico e de colonização nesses 520 anos que tem o país chamado Brasil, provocou várias modificações entre elas o de agregar novos elementos à vida diária e mesmo na performance ritual, mas isso não significou perda de identidade e sim atribuição de novos significados aos elementos da sua cultura material, aos 
aspectos cosmológicos e identitários, mantendo-se firmes na luta para continuarem sendo Tikuna e

Pankararu.

\section{REFERÊNCIAS}

ALBUQUERQUE, Marcos Alexandre dos Santos. O praiá Pankararu: objeto-fetiche modernista In: PROA: Revista de Antropologia e Arte, v. 1, n. 5, 2013/2014. Disponível em: https://www.ifch.unicamp.br/ojs/index.php/proa/article/view/2334. Acesso em: 14 ago 2020.

ALBUQUERQUE, Marcos Alexandre dos Santos. A Intenção Pankararu: a "dança dos praiás" como tradução intercultural na cidade de São Paulo. In: Iluminuras, Porto Alegre, v. 18, n. 43, p.158-187, jan/jul, 2017. Disponível em: https://seer.ufrgs.br/iluminuras/article/view/72881 Acesso em: 15 ago 2020.

BARROS, Antônio Carlos de; STEINER, Andrea Quirino. Recursos Naturais da Caatinga utilizados nos rituais do povo indígena Pankararu (Pernambuco/Brasil). In: OLAM - Ciência \& Tecnologia. Ano XIII, v. 1, n. 2, julho/dez., 2013, p.341-355. Disponível em: http://www.periodicos.rc. biblioteca.unesp.br/index.php/olam/index. Rio Claro/SP. Acesso em: 14 ago 2020.

BOAS, Franz. As limitações do método comparativo da Antropologia (1896). In: CASTRO, Celso. (Org.) Antropologia Cultural: tetos selecionados. $2^{a}$ ed. Rio de Janeiro: Zahar Ed., 2005, p. 25-39.

BRANDÃO, Carlos R. Identidade e Etnia: construção da pessoa e resistência cultural. São Paulo: Brasiliense, 1986.

CAMACHO, Hugo. Máguta, la gente pescada por Yoí. Bogotá: Premios Nacionales de Cultura, Colcultura, 1995.

CAMACHO, Hugo. Nuestras Caras de Fiesta. Bogotá: Tecer Mundo Ed.,1996.

CARDOSO DE OLIVEIRA, Roberto. Identidade, Etnia e Estrutura Social. São Paulo: Biblioteca Pioneira de Ciências. Sociais, 1976.

COSTA, May Anyely Moura da. "Nós, Ticuna, temos que cuidar da nossa cultura": um estudo sobre o ritual de iniciação feminina entre os Ticuna de Umariaçú I, Tabatinga, Alto Solimões (AM). 2015. 122f. Dissertação (Mestrado em Antropologia Social) - Universidade Federal do Amazonas. Manaus, 2015.

DOMINGUES-LOPES, Rita de Cássia. Desvendando significados: contextualizando a coleção etnográfica Xikrín do Cateté. 2002. 99 f. Dissertação (Mestrado em Antropologia) - Universidade Federal do Pará, Centro de Filosofia e Ciências Humanas, Belém, 2002. 
DOMINGUES-LOPES, Rita de Cássia. Identidade Ticuna: (Re)Contextualizando as peças da Coleção Curt Nimuendajú. 2000. 44f. Trabalho de Conclusão de Curso. Graduação em Ciências Sociais - Universidade Federal do Pará, Centro de Filosofia e Ciências Humanas, Belém, 2000.

FAJARDO, Glória \& TORRES, William. Ticuna In: Colombia Amerindia. Bogotá: Instituto Colombiano de Antropologia, 1988.

FAULHABER, Priscila. Interpretando os artefatos rituais Ticuna. In: Revista do Museu de Arqueologia e Etnologia, São Paulo, n.17, p.345-363, 2007.

FROTA, Lélia Coelho. A cultura material do índio brasileiro: Um objeto de conhecimento. In: Coleção Museus Brasileiros - Museu Paraense Emílio Goeldi. vol. 4, RJ: FUNARTE, 1981.

GEERTZ, Clifford. A Interpretação das Culturas. Rio de Janeiro: Zahar Ed., 1978.

GONÇALVES, José Reginaldo Santos. O templo e o fórum - reflexões sobre museus, antropologia

e cultura. In: A invenção do patrimônio: continuidade e ruptura na constituição de uma política oficial de preservação no Brasil. MC/IPHAN. Rio de Janeiro, 1995, p. 55-66.

GRÜBER, Jussara. A arte gráfica Ticuna. In: VIDAL, Lux (Org.) Grafismo indígena: estudo de antropologia estética. São Paulo: Studio Nobel/EDUSP/FAPESP, 1992, p. 249-264.

ISA - Instituto Socioambiental. Enciclopédia dos Povos Indígenas do Brasil. Ticuna. São Paulo. Disponível em: https://pib.socioambiental.org/pt/Povo:Ticuna. Acesso em: 14 ago 2020.

ISA - Instituto Socioambiental. Enciclopédia dos Povos Indígenas do Brasil. Pankararu, São Paulo. Disponível em: https://pib.socioambiental.org/pt/Povo:Pankararu. Acesso em: 14 ago 2020.

LÉVI-STRAUSS, Claude. La via de La Máscaras. $4^{\circ}$ ed. Siglo Veintiuno. Ed. México, 1989.

LODY, Raul. Artesanato: uma visão completa. In: Ciência \& Trópico, Recife, v. 14, n. 2, p. 151155, jul./dez., 1986.

LOWIE, Robert. Franz Boas. In: Historia de la Etnologia. México, Fondo de Cultura Econômica, 1946, p. 159-191. 
MENESES, Ulpiano T. Bezerra de. A cultura material no estudo das sociedades antigas. In: Revista de História. São Paulo, USP, n. 115, p. 103-117, jul/dez., 1983.

MURA, Claudia. "Todo mistério tem dono!" Ritual, política e tradição de conhecimento entre os Pankararu. 2012. Tese (Doutorado em Antropologia Social) - Museu Nacional da Universidade Federal do Rio de Janeiro, 2012.

NIMUENDAJÚ, Curt. The Tucuna. In: Handbook of South American Indians. Bulletin of the Bureau of American Ethnology, vol. 3nº 143, 1959, p 713-725.

OLIVEIRA FILHO, João Pacheco. O nosso governo - os Ticuna e o regime tutelar. São Paulo: Marco Zero; Brasília, DF: MCT/CNPq, 1988.

RIBEIRO, Berta G. Etnomuseologia: da coleção à exposição. In: Revista do Museu de Arqueologia e Etnologia, São Paulo, vol. 4, p. 189-201, 1994.

RIBEIRO, Berta G. Cultura Material: Objetos e Símbolos. In: Ciências em Museus. Belém, MPEG, v. 2. n 1. p. 17-25, out./ 1990.

RIBEIRO, Berta G. Dicionário de Artesanato Indígena. Belo Horizonte/São Paulo: Itatiaia/EDUSP, 1988.

RIBEIRO, Berta G. Os estudos de cultura material: propósitos e método. In: Revista do Museu Paulista. São Paulo, USP, v. XXX, n. 30, p. 13-41, 1985.

VINCENT, William Murray. Máscaras. Objetos rituais do alto Rio Negro. In: Suma Etnológica Brasileira - Arte Índia. Vol. III. $2^{\circ}$ ed. Petrópolis: Vozes/Finep, 1987, p 151-156. 
